\title{
SPECTRAL STRUCTURE OF HIGH FREQUENCY $P$ AND S PHASES OBSERVED BY OBS'S IN THE MARIANA BASIN
}

\author{
Toru OuchI \\ Department of Earth Sciences, Faculty of Science, \\ Kobe University, Kobe, Japan \\ (Received November 6, 1978; Revised July 11, 1981)
}

The spectral content of high frequency $(1-30 \mathrm{~Hz}) \mathrm{P}$ and $\mathrm{S}$ phases observed by ocean bottom seismographs (OBS's) in the Mariana basin is investigated. It is shown that autoregressive models of 10-30th order are suitable for analyzing high frequency waves. For events with S-P times greater than $50 \mathrm{sec}$, both the predominant frequency and the wave energy of observed $P$ and $S$ phases are confined to a narrow range, say $6-10 \mathrm{~Hz}$ for $\mathrm{P}$ waves and $5.5-9 \mathrm{~Hz}$ for $\mathrm{S}$ waves. In addition, high frequency phases are also characterized by their long duration. It seems likely that some intrinsic property of the oceanic crust or upper mantle allows the efficient transmission of high frequency $(5-10 \mathrm{~Hz})$ seismic waves. A model of the oceanic upper mantle which is consistent with the observed transmission of high frequency seismic waves is presented.

\section{Introduction}

The transmission of high frequency $\mathbf{P}$ and $\mathbf{S}$ phases over a long distance is one of the most interesting phenomena in seismology. These phases have been observed by several investigators both in oceanic regions (BARAZANGI et al., 1972; WALKer and Sutton, 1971; Walker, 1977a, b; AsAda and ShIMAMURA, 1976) and continental regions (ShURBET, 1962, 1964; BrUNE and DorMAN, 1963; BÅTH, 1966) or along deep earthquake zones (OLIVER and ISACKS, 1967; UTSU, 1967; Mitronovas et al., 1969; Molnar and Oliver, 1969; Barazangr et al., 1972; KHALturin et al., 1977).

In general, these high frequency phases are considered to be propagated in the uppermost mantle and have thus been called " $\mathrm{P}_{n}$ " and " $\mathrm{S}_{\mathrm{n}}$ ". However, the nature of these phases is not well understood, so that it is not certain whether or not they are similar to ordinary $P_{n}$ and $S_{n}$ phases in all aspects. For convenience's sake we shall write all observed phases simply as " $P$ " and " $S$ " waves instead of " $P_{n}$ " and " $S_{n}$ " in this paper.

The main purpose of this paper is to investigate the spectral structure of high frequency $\mathrm{P}$ and $\mathrm{S}$ waves observed by ocean bottom seismographs (OBS's) in the Mariana basin. These results of analysis may enable us to understand the 
effect of layered crust-mantle structure on the propagation of seismic waves in oceanic regions.

\section{Data and Methods of Analysis}

\subsection{Collection of data}

Ocean bottom seismograph data used in this paper were collected in two cruises; the KH-73-4 Hakuho-Maru cruise (July-August, 1973) and the KH-76-1 Hakuho-Maru cruise (January-February, 1976). On the occasions of these cruises, OBS's were set up in the central part of the Mariana basin (see, Fig. 1 and Table 1).

For the analysis reported here, the data from stations St-5 (1973) and St-3 (1976) were selected because these two stations were equipped with geophones with a resonant frequency $1 \mathrm{~Hz}$ and recording systems of the open reel type (NAGUmo et al., 1970), and so their frequency as well as dynamic ranges were excellent. The frequency response curves of these OBS systems are shown in Fig. 2. In the case of the 1976 experiment, the system covered a $1-40 \mathrm{~Hz}$ range and so the spectral properties of seismic waves in this range can be analyzed without correction. For the 1973 experiment (St-5), however, the frequency range is much narrower $(1-15 \mathrm{~Hz})$.

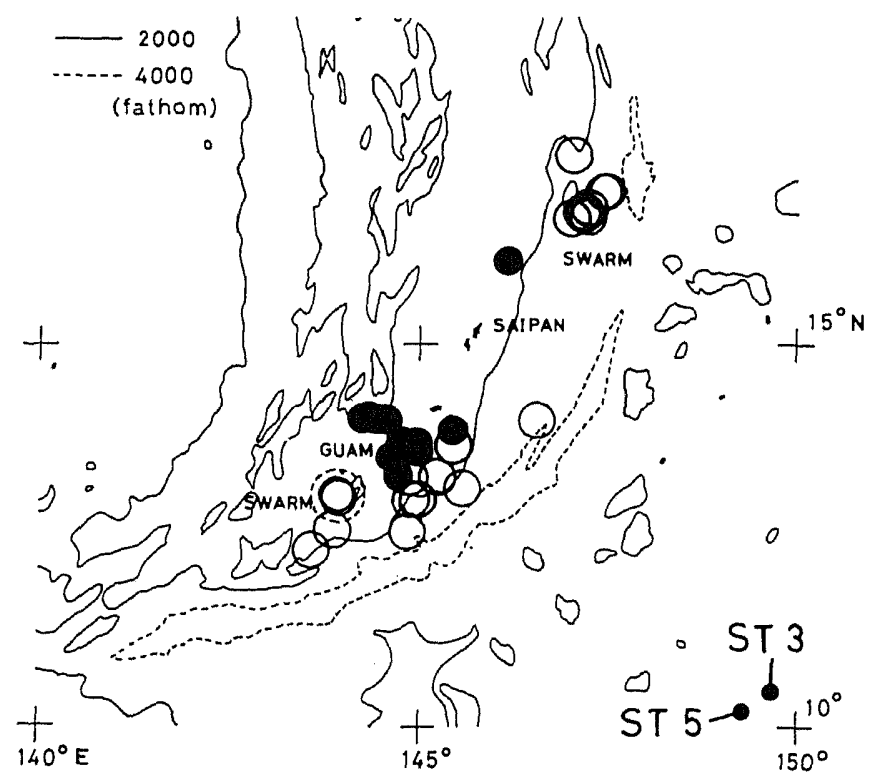

Fig. 1. Bathymetric map of the Mariana island arc region showing positions of ocean bottom seismographs that recorded the data analyzed in this paper. Epicenter distribution of microearthquakes during the period from January 21 to 30,1976 (OucH et al., 1981) is also shown. Open circles show the events shallower than $70 \mathrm{~km}$ and solid circles denote the earthquakes with depths from 70 to $150 \mathrm{~km}$. 
Table 1

\begin{tabular}{|c|c|c|c|c|c|}
\hline \multirow{2}{*}{ Station } & \multicolumn{2}{|c|}{ Location } & \multirow{2}{*}{$\begin{array}{c}\text { Altitude } \\
(\mathrm{m})\end{array}$} & \multicolumn{2}{|c|}{ Observation period } \\
\hline & Lat. (N) & Long. (E) & & from & to \\
\hline $\begin{array}{l}1973 \\
\text { St-5 } \\
1976\end{array}$ & $10^{\circ} 11^{\prime} 7$ & $149^{\circ} 16^{\prime} 7$ & $-5,585$ & July $18 \quad 10: 30$ & Aug. $\quad 2$ 09: 30 \\
\hline St-3 & $10^{\circ} 28^{\prime} 2$ & $149^{\circ} 44^{\prime} 2$ & $-5,750$ & Jan. $2213: 50$ & Jan. $3109: 00$ \\
\hline
\end{tabular}

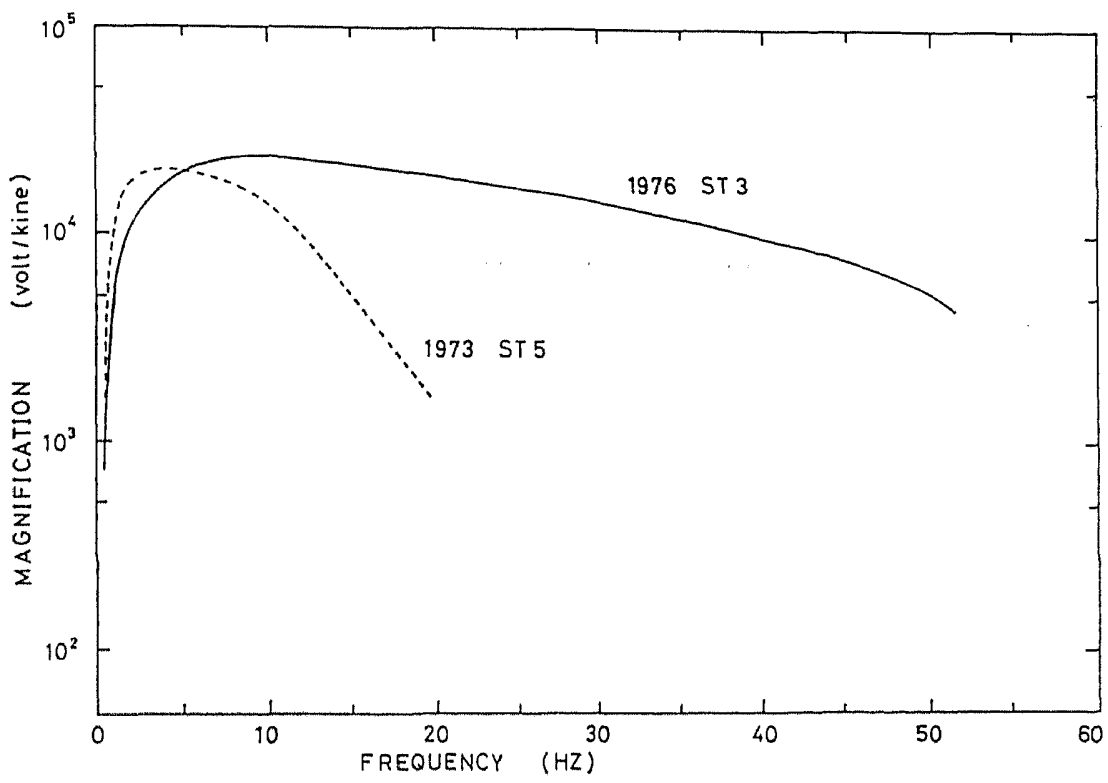

Fig. 2. System frequency response curves of OBS St-5 (1973) and St-3 (1976).

The spectral amplitude of the background noise increases steeply for frequencies below about $4 \mathrm{~Hz}$ and has an apparent peak around $1 \mathrm{~Hz}$ (Fig. 3). A sharp peak around $16 \mathrm{~Hz}$ is believed to be generated by the OBS system, because the peak always appears at almost the same frequency band in the noise spectrum.

Twenty-five high frequency $\mathrm{P}$ and $\mathrm{S}$ phases recorded by vertical component geophones have been analyzed. S-P times of these earthquakes range from 10 to $120 \mathrm{sec}$. Most earthquakes with S-P times of 50-70 sec at St-5 (1973) and St-3 (1976) occurred along the Mariana island arc (Fig. 1). Source depths are from the surface to about $150 \mathrm{~km}$. Earthquakes having S-P times less than $40 \mathrm{sec}$ seem to locate shallow in the Caroline region. Other earthquakes with S-P times longer than $70 \mathrm{sec}$ appear to be located in the other regions of the Mariana island arc (NAGUMO and KaSAFARA, 1976; OUCHI et al., 1981).

The maximum magnitude reported by USGS is $M b=4.4$ (Fig. 4). If we apply WATANABE's formula (1971), 


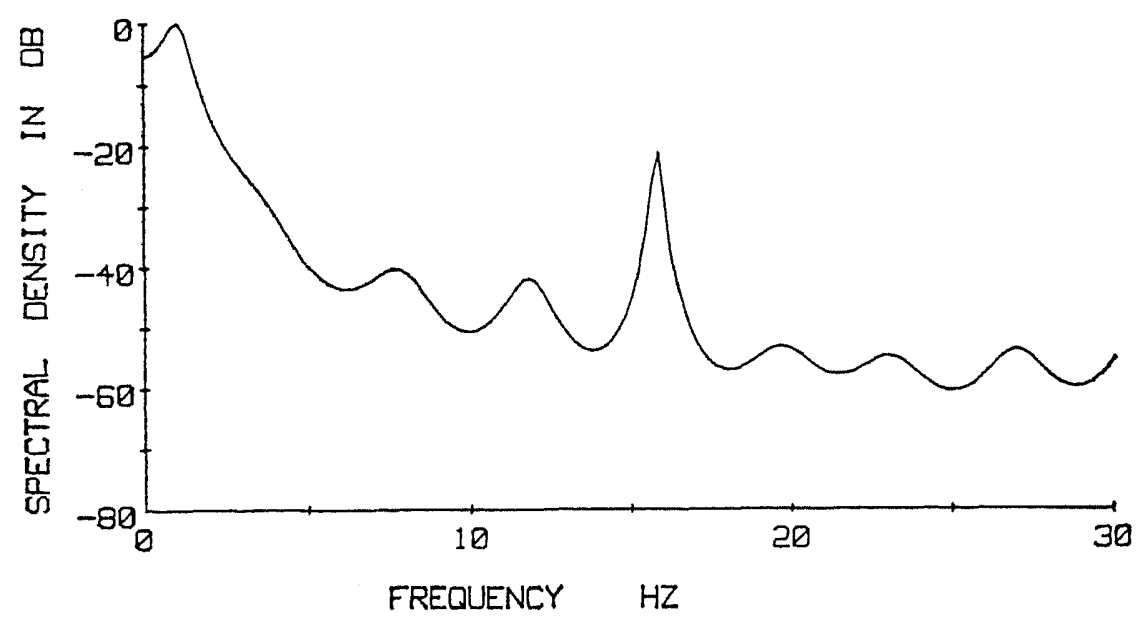

Fig. 3. Background noise spectrum observed on the floor of the Mariana basin on July 23,1973 . The peak around $16 \mathrm{~Hz}$ is apparently due to the system noise.

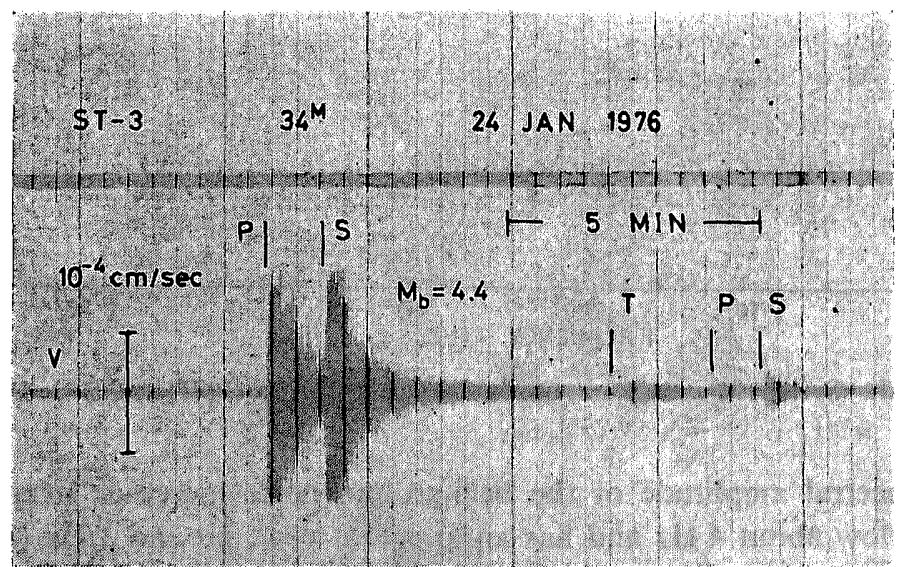

Fig. 4. Example of an earthquake recorded at OBS St-3 (1976). Note its long duration.

$$
0.85 M-2.5=\log A v+1.73 \log r+0.0015(r-200),
$$

where $A v$ denotes the maximum velocity amplitude of the seismic trace and $r$ is the distance in $\mathrm{km}(r \geq 200 \mathrm{~km})$, the calculated magnitudes range from 3 to 5.5 . However, the calculated values may be larger than the actual magnitudes because of the extremely efficient transmission of seismic waves in oceanic regions.

We have analyzed the initial 3 to $8 \mathrm{sec}$ of $P$ and $S$ phases with sampling intervals of 5.7-6 msec. To eliminate background noise effects below $2 \mathrm{~Hz}$ and above $30 \mathrm{~Hz}$, a Chebycheff's band pass filter (2-30 Hz) (AsHIDA and SAITO, 1970) 
was applied to the data before the spectral analysis. We avoided the contamination of the noise around $16 \mathrm{~Hz}$ by choosing earthquakes which had a large signal to noise ratio.

\subsection{Autoregressive models}

We have applied autoregressive (AR) models to the spectral analysis of seismic waves. An AR process of order $m$ is represented as follows

$$
\begin{gathered}
X_{t}+a_{1 m} X_{t-1}+a_{2 m} X_{t-2}+\cdots \quad \cdots+a_{m n} X_{t-m}=\varepsilon_{t} \\
E\left[X_{t}\right]=0, \quad E\left[\varepsilon_{t}\right]=0,
\end{gathered}
$$

where $X_{t}, X_{t-1}, \cdots, X_{t-m}$ are sampled time series and $a_{1 m}, a_{2 m}, \cdots, a_{m m}$ are AR coefficients. $\quad \varepsilon_{t}$ is white noise and $E[$ ] denotes the ensemble average.

The spectral density of an AR process is given by

$$
P(f)=\sigma_{\varepsilon}{ }^{2}\left|f_{N}\right| 1+\left.\sum_{j=1}^{m} a_{j m} \exp (-i 2 \pi f j \Delta t)\right|^{2},
$$

where $\sigma_{s}^{2}, f_{N}$ and $\Delta t$ are the variance of $\left\{\varepsilon_{t}\right\}$, Nyquist frequency and the sampling interval, respectively. This formula is also well known as the maximum entropy spectral estimate method (e.g., ULRYCH and BrsHop, 1975; OUCHI and NAGUMO, 1975).

In general, high frequency $\mathrm{P}$ and $\mathrm{S}$ wave trains observed at the bottom of the Mariana basin consist of superpositions of many arrivals together with background noise and, if a particular limited interval is considered, they can be regarded as stochastic and local stationary processes. In addition, we must determine the spectral properties from only a finite short portion of the record since the nature of the waves may change with time. For these reasons, we have introduced the stochastic AR method for the analysis of high frequency $\mathrm{P}$ and $\mathrm{S}$ phases obtained by OBS's. In practice, this method seems much superior for addressing the above problems to the more commonly used methods such as the conventional Fourier analysis.

In the practical application of AR models to seismic waves, however, two difficult problems arise. One is what order of AR model should be fitted to the data and the other is whether the AR model is appropriate or not at all. Box and JENKINS (1970) discussed these problems and showed that if the autocorrelation of the data presents damped sinusoidal character and if the partial autocorrelation dies out quickly enough, the AR model is appropriate. The partial autocorrelation coefficients which have values the same as $a_{m m}$ of $\mathrm{AR}$ coefficients are easily obtained by a recursive method (see Box and JENKINS, 1970). It has also been shown that the order of the AR model can be determined by the trend of the partial autocorrelation (see also TృøSTHEIM, 1975). In other words, if the process is an AR of order $m$, the standard error (SE) of the estimated partial autocorrelation $a_{k k}$ of $m+1$ and higher is

$$
\left[a_{k k}\right] \simeq 1 / \sqrt{ } N, \quad k \geqq m+1,
$$



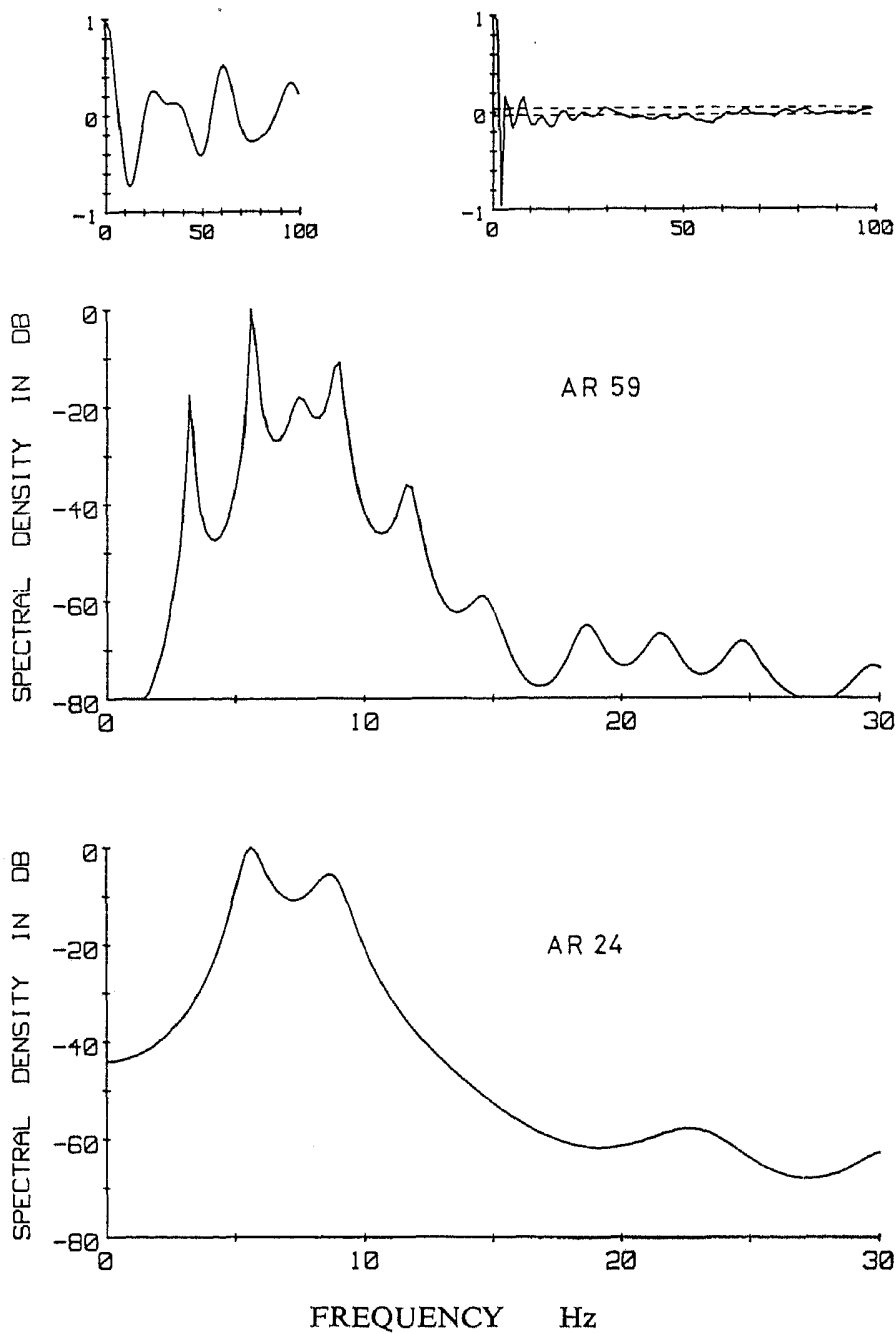

Fig. 5. Comparison of $P$-wave spectra $(S-P=59.2 \mathrm{sec})$ for high order $(A R=59)$ and low order $(A R=24)$ models. Note the variations of the spectral shapes with the AR order. The FPE is minimum for AR 59 model. The autocorrelation (left) and the partial autocorrelation (right) are shown at the top. The dotted lines denote the standard error (SE) levels.

where $N$ is the total number of observations. Thus if the estimated partial autocorrelation is close to zero for all lags $k>m$, we may regard that the process $\left\{X_{t}\right\}$ is an AR order $k$.

In most cases treated in this paper, autocorrelations show almost damped sinusoidal characters and partial autocorrelations die out within the SE level between the AR order of 20 and 30. Hence AR models seem quite suitable in 
most cases and determinations of AR orders seem also adequate.

A different method for determining the order of AR models by minimizing the final prediction error (FPE) was proposed by AKAIKE (1969a, b). However, we found that in most cases the orders determined by both the methods were nearly the same.

In some cases, the partial autocorrelation does not fall off easily and FPE does not reach the minimum value readily. But, even so, it is not desirable to use higher order models, because a model, of which the order is too high, introduces spurious detail into the spectral estimate (ULRYCH and BISHOP, 1975; OUCHI and Nagumo, 1975). Hence, in such cases, we adopted the order for which the partial autocorrelation first converges within the SE level. By doing so, we can obtain an appropriate spectral estimate except detailed points.

We illustrate the effect of the AR order in the spectral shapes in Fig. 5. The FPE is minimum for AR 59 model but AR 24 model is chosen in this study by the criterion mentioned above. Using AR models of order $10-30, \mathrm{P}$ and $\mathrm{S}$ waves observed at the sea bottom of the Mariana basin can be analyzed quite successfully.

\subsection{Spectral structure and predominant frequency}

High frequency $\mathrm{P}$ and $\mathrm{S}$ phases are in general characterized by a sinusoidal appearance and a duration of several minutes (Fig. 6a). These features seem to be independent of the magnitude of the shock or the source depth. It is surprizing that most earthquakes at great distances present spectral shapes and predominant frequencies (Fig. 6b) similar to those for moderately distant earthquakes. Meanwhile, the spectra seem to depend on the epicentral distance. For most

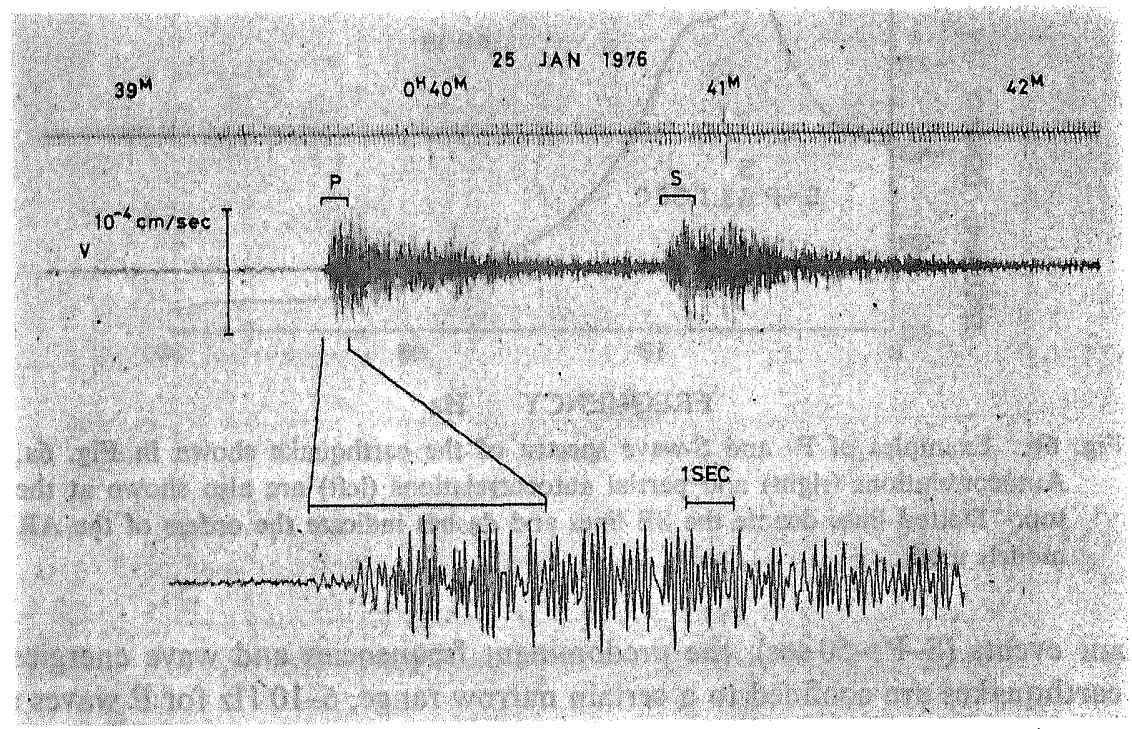

Fig. 6a. An example of the high frequency $P$ and $S$ phases $(S-P=69.1 \mathrm{sec})$. 

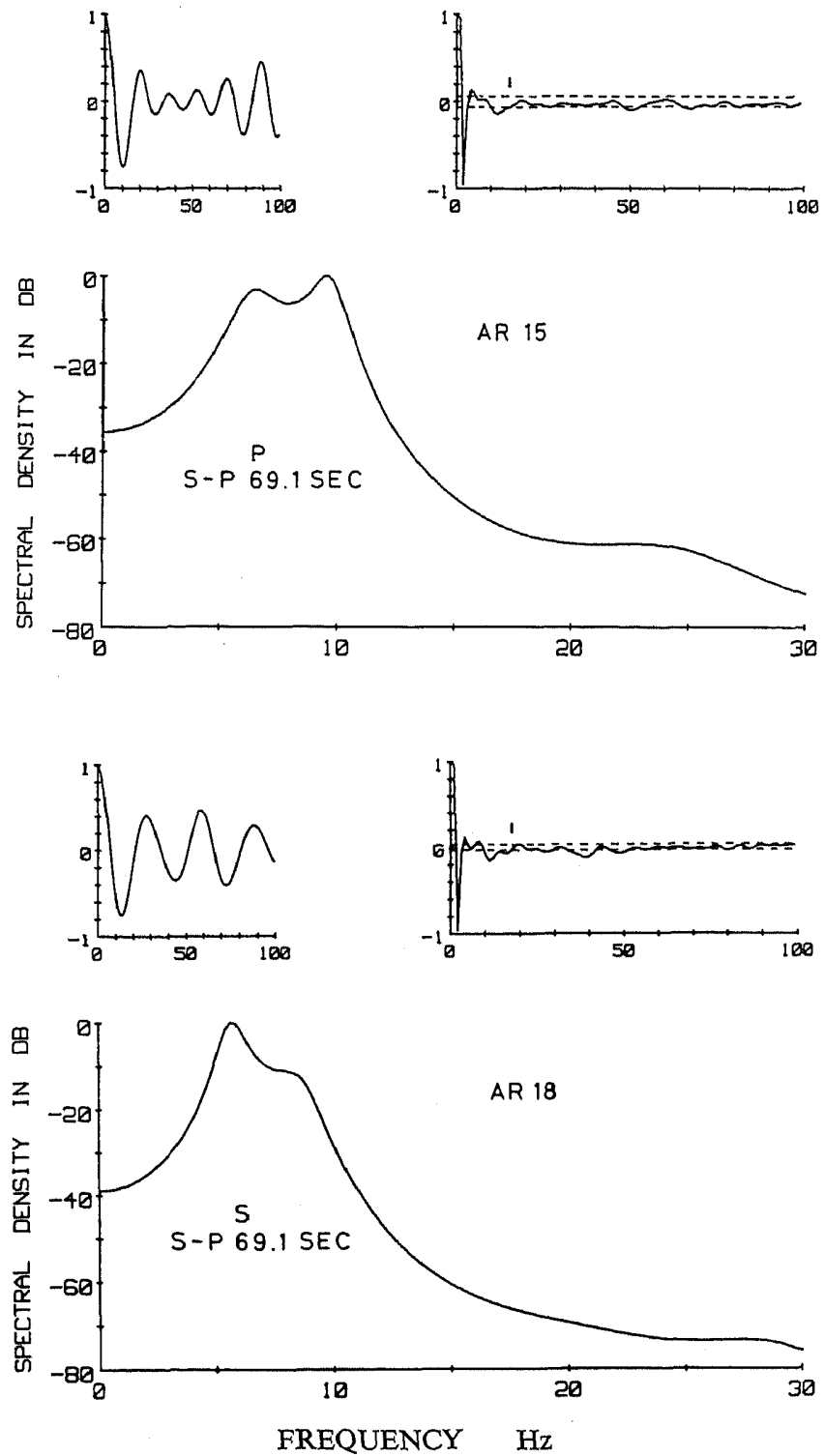

Fig. 6b. Examples of P- and S-wave spectra of the earthquake shown in Fig. 6a. Autocorrelations (right) and partial autocorrelations (left) are also shown at the top. Dotted lines denote the SE lines and dashes indicate the orders of the AR models used.

distant events $(\mathbf{S}-\mathrm{P}>50 \mathrm{sec}$ ), the predominant frequencies and wave energies of the earthquakes are confined to a certain narrow range, $6-10 \mathrm{~Hz}$ for $\mathrm{P}$ waves and 5.5-9 $\mathrm{Hz}$ for $\mathrm{S}$ waves (Figs. 7a, b). 


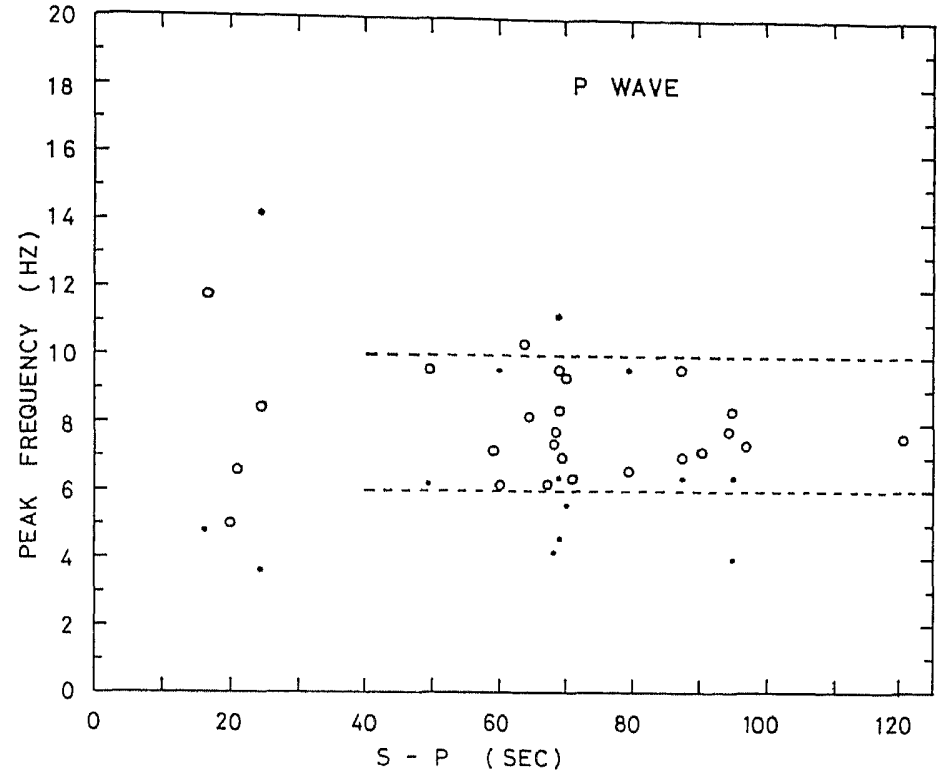

Fig. 7a. Relation between peak frequencies of $P$ waves and S-P times observed at the Mariana basin. Open circles denote prominent peaks and solid circles show other peaks.

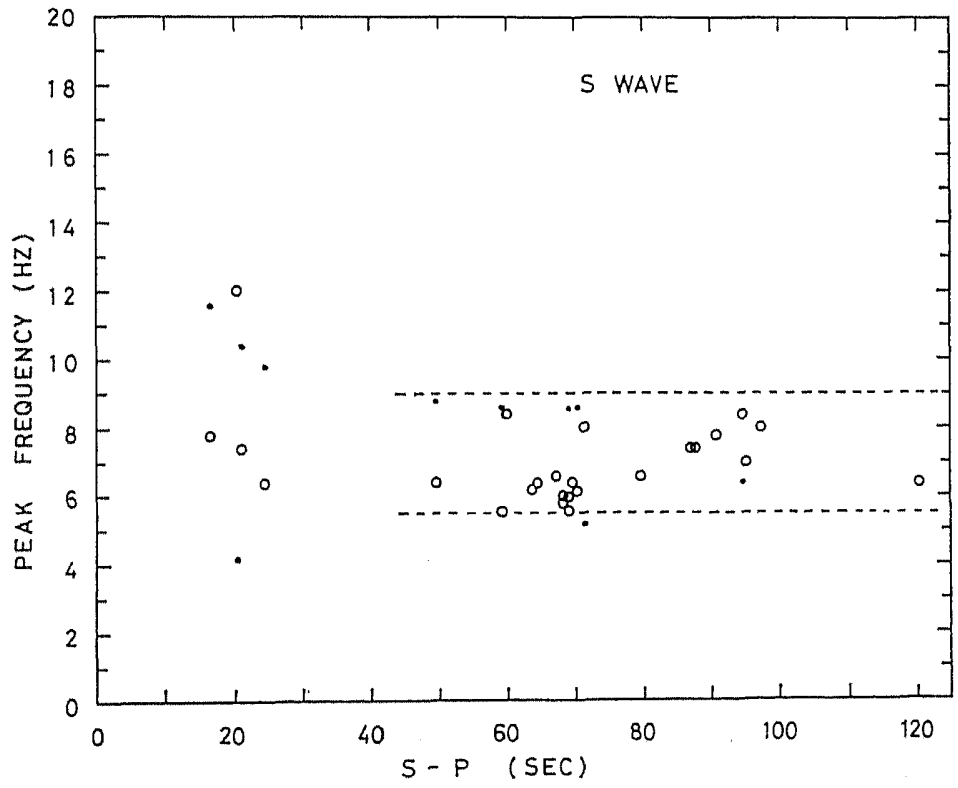

Fig. 7b, Relationship between peak frequencies of $\mathrm{S}$ waves and $\mathrm{S}-\mathrm{P}$ times. 

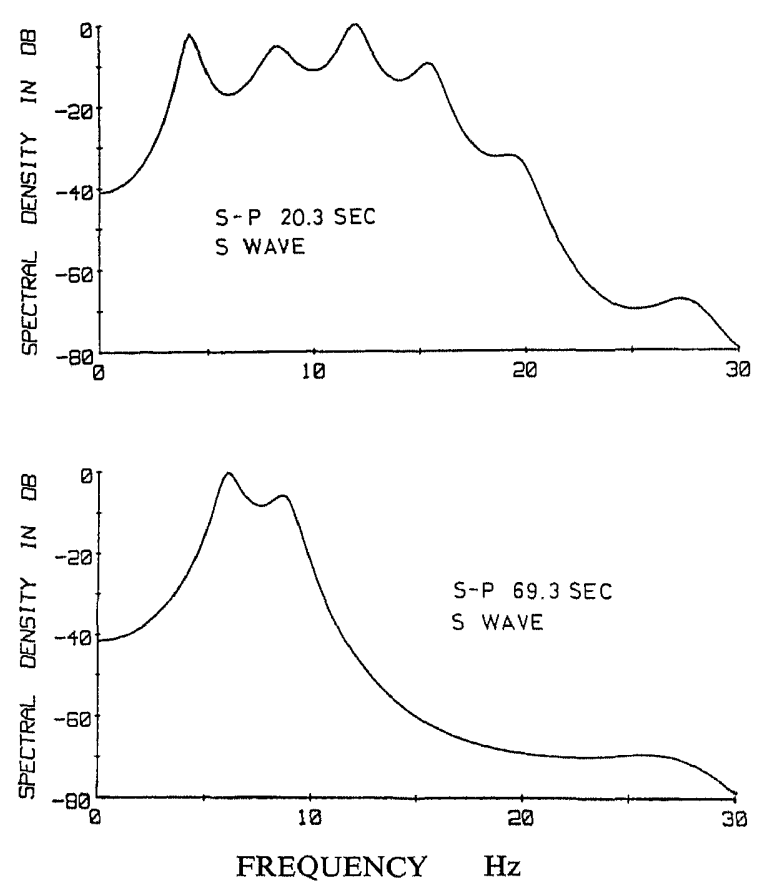

Fig. 8a. Comparison of S-wave spectra observed by OBS St-5 on August 2, 1973 (top: $\mathrm{S}-\mathrm{P}=20.3 \mathrm{sec}$ ) and OBS St-3 on January 25, 1976 (bottom: $\mathrm{S}-\mathrm{P}=69.3 \mathrm{sec}$ ). The nearer event (top) has much wider spectral contents than the distant event (bottom), though in the 1973 observation (top) the frequency response of the OBS system is restricted in a narrow range (Fig. 2).

In contrast, peak frequencies and spectra of the events whose S-P times are less than 30 to $40 \mathrm{sec}$ scatter considerably. These spectral variations are clearly seen in the spectral patterns (Figs. 8a, b).

It appears that the high frequency $P$ and $S$ phases have almost identical spectral properties when recorded at long distances. It should also be noted that spectra of $\mathbf{P}$ and $S$ waves do not vary significantly with time (Figs. 9a, b). There is no apparent dispersion in either the P-or-S wave trains. These characteristics imply that there is some mechanism which effectively filters $P$ and $S$ waves during the propagation in oceanic regions and that a sharpening of the spectra between $5-10 \mathrm{~Hz}$ consequently occurs.

\subsection{Duration}

A notable feature of seismic waves observed at the sea bottom is their long durations lasting several minutes. For example, the total duration of a magnitude 4.4 event observed at a distance of about $750 \mathrm{~km}$ is more than $5 \mathrm{~min}$, even if the $T$ phase is excluded (Fig. 4).

The duration of earthquakes observed on the sea bottom is considerably 

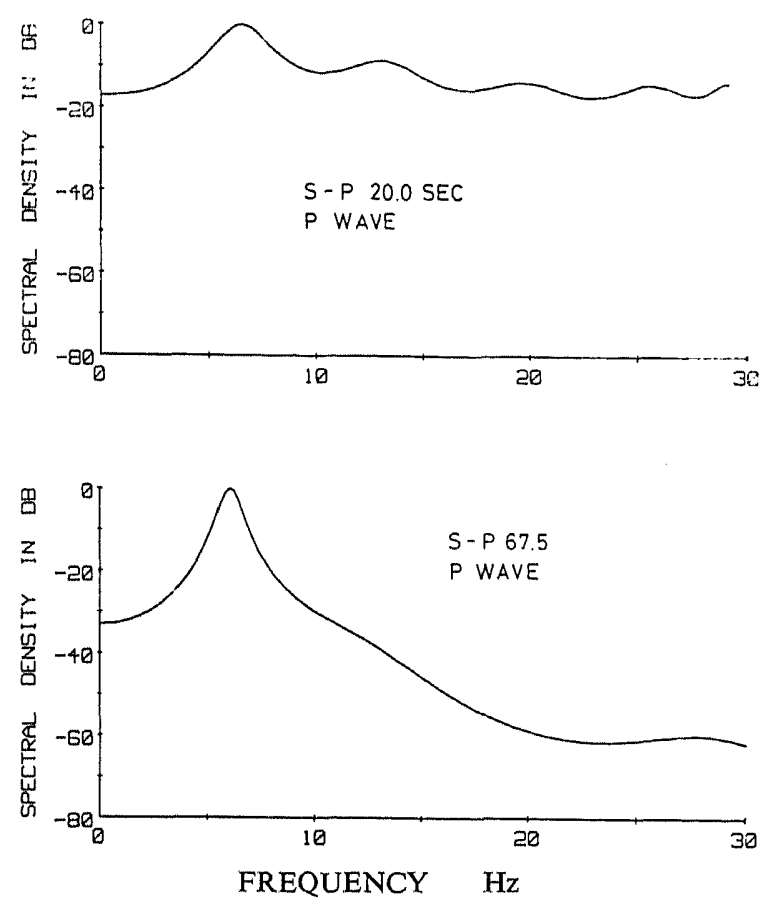

Fig. 8b. Comparison of P-wave spectra observed by St-3 on January 26, 1976 (top: S-P $=20.0 \mathrm{sec}$ ) and January 24, 1976 (bottom: $S-P=67.5 \mathrm{sec}$ ).

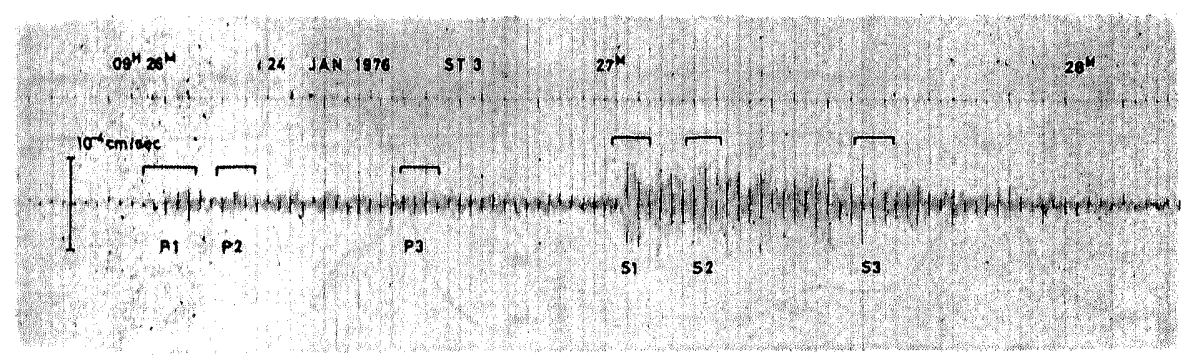

Fig. 9a. Record of an earthquake at St-3 (1967). S-P time is about $60 \mathrm{sec}$.

longer than those observed on land. TSUMURA (1967) obtained the following empirical formula for events recorded at the Wakayama region.

$$
M=-2.57+2.85 \log D+0.0014 \Delta,
$$

where $M$ is the magnitude of Japan Meteorological Agency (JMA), $D$ is the duration of earthquakes in seconds and $\Delta$ is the distance in kilometers. For typical values from our data $(\Delta=700 \mathrm{~km}$ and $D=3-4 \mathrm{~min})$, the magnitude becomes about 5 according to his formula. This value of magnitude seems too large 

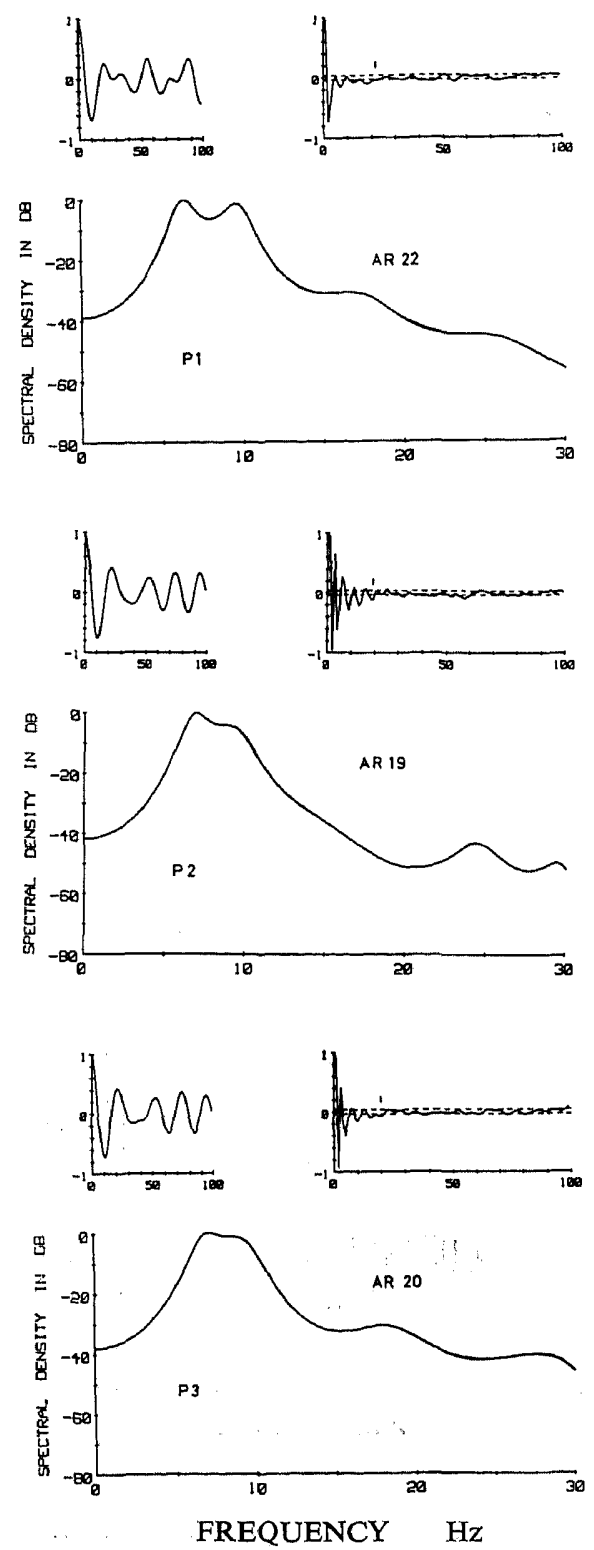

Fig. 9b. P-and S-wave spectra of the intervals $\left(\mathrm{P}_{1}-\mathrm{S}_{8}\right)$ shown in Fig. 9 a.

because most magnitudes of earthquakes estimated from the WATANABE's formula (1971) or the reported magnitude by USGS are much smaller than 5. Even if the difference in the definition of the magnitude is taken into account, it can be said that the duration of seismic waves recorded on the sea bottom is much longer than those observed on land. 


\subsection{Forerunner}

In some cases of high frequency $\mathrm{P}$ phases, low frequency $(3-5 \mathrm{~Hz})$ wave trains appear just prior to the arrival of main $P$ phases (Fig. 10a). The time intervals between these two arrivals are 2-3 sec, for example. Such forerunners have been already found by LATHAM and SUTTON (1966) and they are interpreted as the normal mantle $P$ phases.

The spectrum of the forerunner phase has a sharp peak around $4 \mathrm{~Hz}$ while the spectrum of the main $P$ phase has rather broad peak between 6 and $8 \mathrm{~Hz}$ (Fig. 10b). There is also a peak at about $4 \mathrm{~Hz}$ in the spectrum of main $\mathrm{P}$ phase.

\subsection{T phase}

$\mathrm{T}$ phases are characterized generally by a peculiar spindle-shaped appearance (Fig. 11a). $\mathrm{T}$ phase spectra contain frequency components wider and higher than those of $P$ and $S$ waves (Fig. $11 \mathrm{~b}$ ). Hence it seems likely that much wider and higher frequency components are generated at the origin.

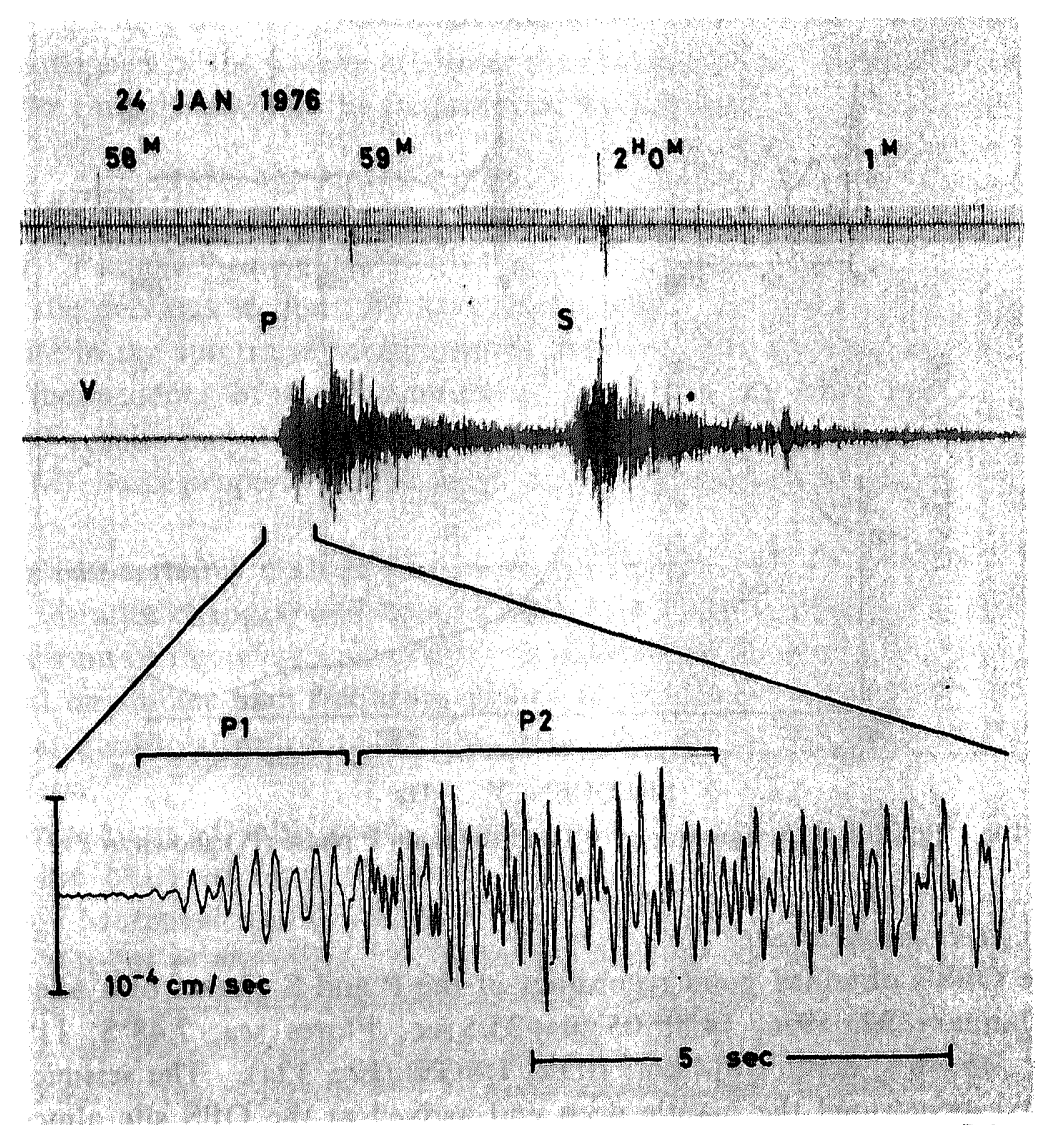

Fig. 10a. Digitized record of a event with a low frequency forerunner $\left(\mathbf{P}_{1}\right)$. 

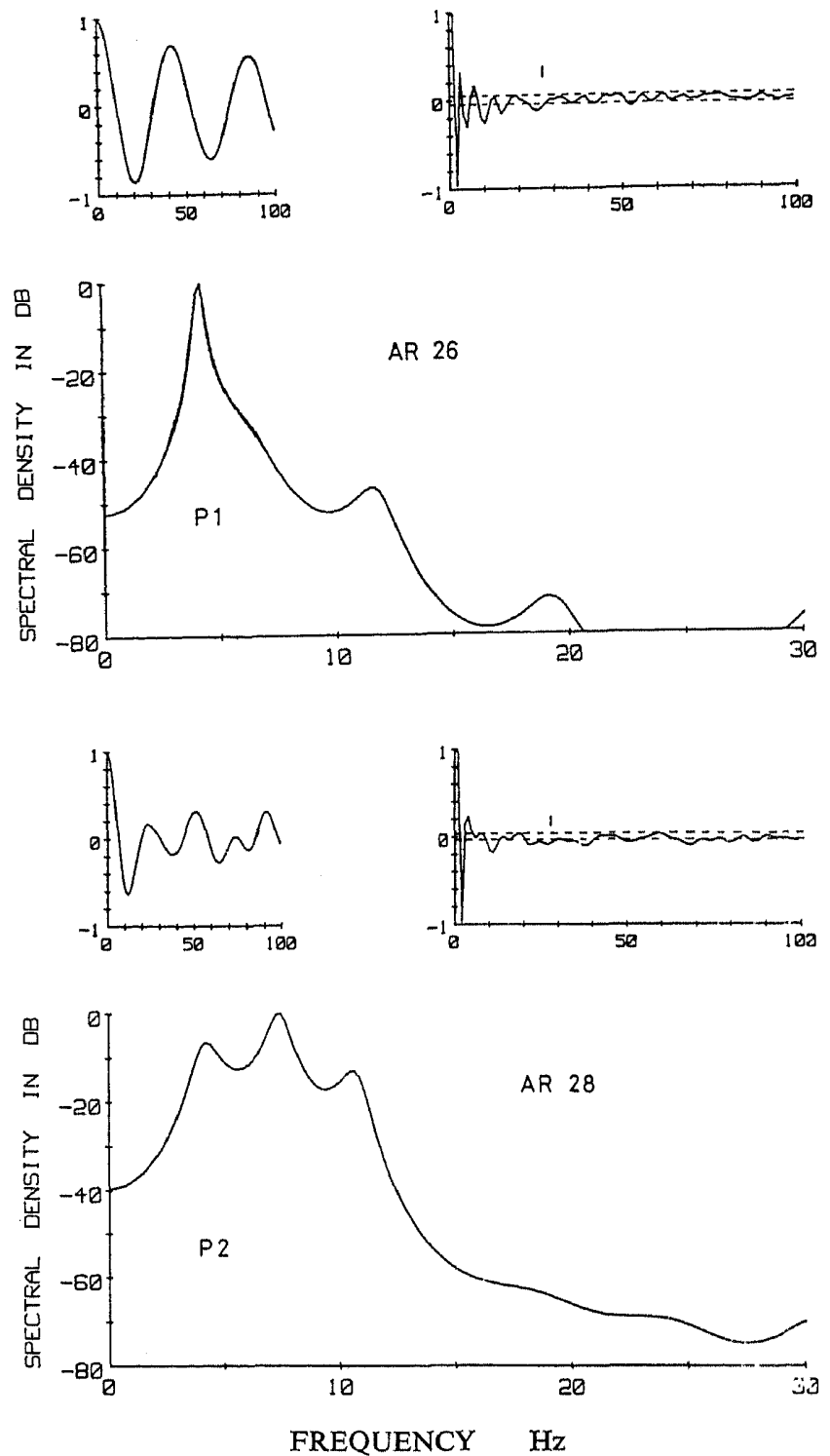

Fig. 10b. Spectra of the forerunner $\left(P_{1}\right)$ and the main $P$ phase $\left(P_{2}\right)$ shown in Fig. 10a.

\subsection{Teleseismic event}

The OBS's obtained good recordings of the $\mathrm{P}$ and $\mathrm{S}$ phases of a teleseismic event (January 23, 1976, $14 \mathrm{hr} 05 \mathrm{~min} 35.5 \mathrm{sec}$; Flores sea, $7.48^{\circ} \mathrm{S}, 119.91^{\circ} \mathrm{E}$, $\Delta=27^{\circ} ; M b=6.4$, depth $=614 \mathrm{~km} ;$ EDR, USGS) (Fig. 12a). The seismic waves must have penetrated the mantle deep and arrived at the OBS site almost perpendicularly to the sea bottom. The spectra for each phase of $P_{1}, P_{2}$ an $S$ are very 


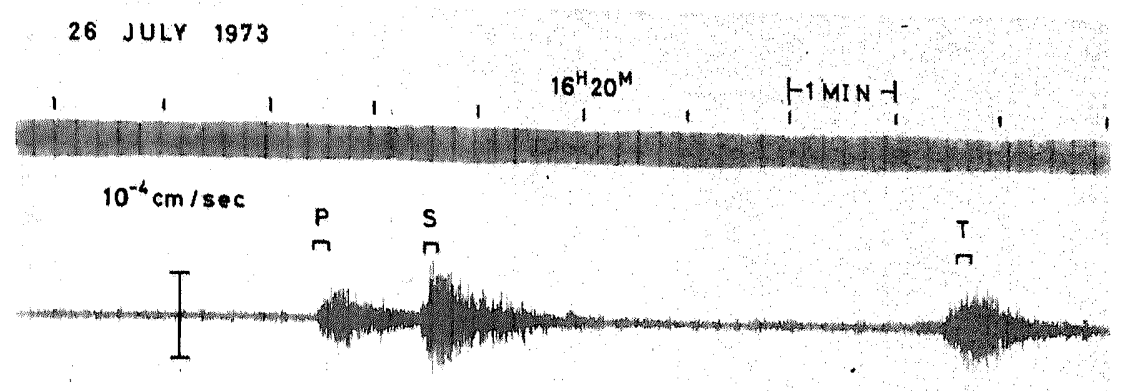

Fig. 11a. Example of a microearthquake with T phase observed at St-5 (1973).

similar to those of background noise shown in Fig. 3 and have an apparent peak around $1 \mathrm{~Hz}$ (Fig. 12b). The high frequency energy mentioned in the previous sections can be hardly seen.

The $\mathrm{S}$ wave amplitude of the teleseismic event is smaller than that of the $\mathrm{P}$ wave. This may be due either to stronger attenuation for the $S$ wave or the fact that frequencies of the $S$ wave are lower than those of the $P$ wave and our system has lower magnification at the frequency of the $S$ wave.

\section{Discussion}

\subsection{Possible "wave guide"}

In the previous sections, we have shown that $5-10 \mathrm{~Hz}$ frequency components dominate in the spectra of seismic waves observed at the bottom of the Mariana basin, independent of the magnitude of shock and the focal position. These observed results may be reasoned by several ways such as (i) site effect of the OBS's, (ii) source properties of the shock; and (iii) propagation effect of the oceanic region.

We can certainly exclude (i) because the spectral pattern changes if the epicentral distance changes, and because such high frequencies are not observed in the spectrum of the teleseismic event. In addition to the above, WALKER (1977a) reported on similar high frequency phases of $3-8 \mathrm{~Hz}$ for earthquakes which occurred at distances from 8 to $30^{\circ}$ and were recorded on the island of Ponape in Micronesia.

Explanation (ii) also seems to be inadequate because the high frequency phases are observed for earthquakes occurring in a wide variety of tectonical settings. Moreover, the depth of these events ranges from the surface to about $150 \mathrm{~km}$ (OUCHI et al., 1981). It is also theoretically implausible that such sinusoidal and long duration waves are generated at the source.

For the above reasons, we conclude that propagation effects are the most likely cause of the observed 5 to $10 \mathrm{~Hz} \mathrm{P}$ and $\mathrm{S}$ phases. The long duration of 

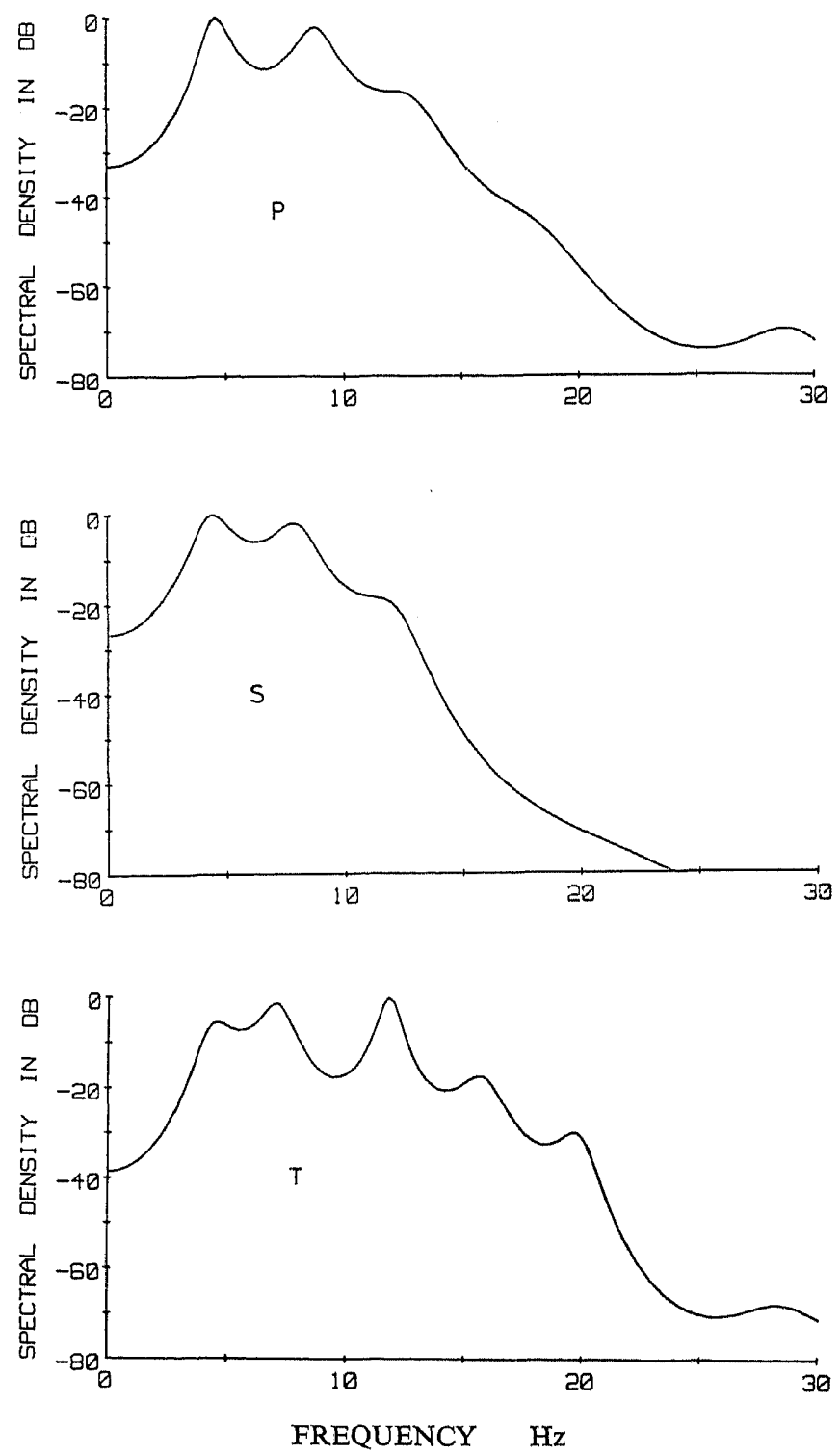

Fig. 11b. Spectra of $\mathbf{P}, \mathrm{S}$ and $\mathrm{T}$ phases shown in Fig. 11a.

these phases suggests the existence of some intrinsic mechanism peculiar to oceanic regions as well. Apparently, these phases are travelling along a "wave guide" (e.g., SUtTON and WALKer, 1972) or a "wave trap" (HIRN et al., 1973).

The nature of the forerunners is not yet certain. They may be "normal mantle P phases" as is suggested by. LATHAM and SutTon (1966). 


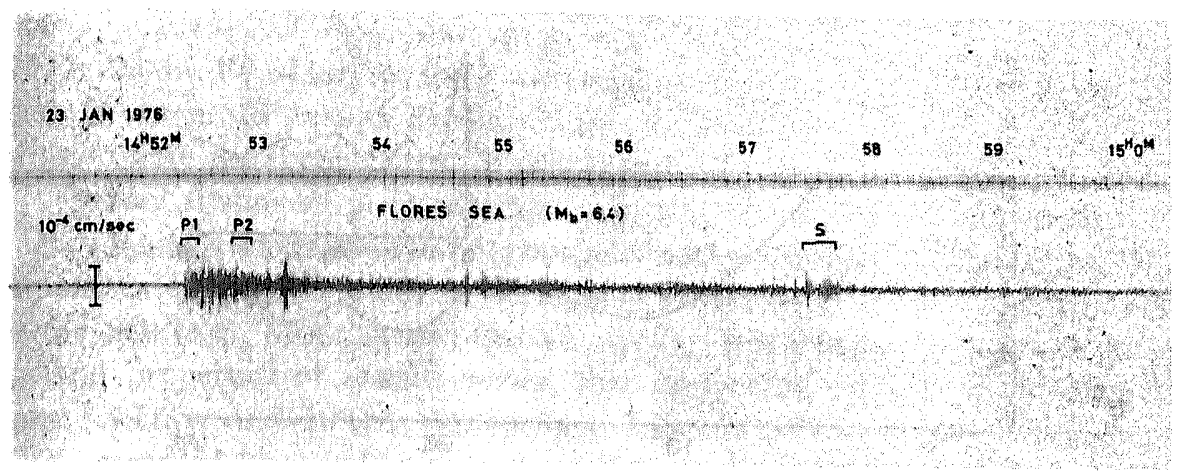

Fig. 12a. Teleseismic event (Flores sea, $M b=6.4, \Delta=27^{\circ}$ ) observed at St-3 (1976):

\subsection{Frequency characteristics and other related phenomena}

As mentioned earlier, high frequency seismic waves have been reported not only in oceanic regions but also in continental regions and near subduction zones. We may raise two questions about these phenomena. First, is the same mechanism responsible for all phenomena? Second, what is the physical significance of the frequency $5-10 \mathrm{~Hz}$ ?

From the published observations, it appears that "high frequency phases" are divided into at least two groups with different frequency modes. One group has a frequency around $1 \mathrm{~Hz}$ and another is above $5 \mathrm{~Hz}$.

ShURBET $(1962,1964)$ observed on recordings on the North American continent that frequencies of about 5 to $6 \mathrm{~Hz}$ dominate for Burmuda earthquakes, compared with about 1.5 to $2 \mathrm{~Hz}$ from events occurring in Central America. On the Russian platform about $0.8 \mathrm{~Hz}$ is reported for " $\mathrm{P}_{\mathrm{n}}$ " and " $\mathrm{S}_{\mathrm{n}}$ " phases which travelled more than $4,000 \mathrm{~km}$ (BÅTH, 1966). About 0.5 to $3 \mathrm{~Hz}$ is observed for " $\mathrm{S}_{\mathrm{n}}$ " waves travelling across the oceanic regions or along the deep earthquake zones (Molnar and Oliver, 1969; Mitronovas et al., 1969; StePhens and IsACKS, 1977). SUTTON and WALKER (1972) reported 3-8 Hz in the north Pacific in the range from 8 to $30^{\circ}$.

High frequency phases of $5-10 \mathrm{~Hz}$ observed in the Mariana basin seem to be the same ones reported by SUTTON and WALKer (1972) and WALKER (1977a) on the island of Ponape. LATHAM and Sutron (1966) observed high frequency waves of the same kind having a frequency range $10-11 \mathrm{~Hz}$ in the OBS study at Burmuda.

As only few of these investigators performed a strict spectral analysis of their data, however, it is not absolutely certain that Shurbet $(1962,1964)$ and SUTTON and WALKER (1972) or WALKER (1977a) have observed the phases the same as those reported in this paper.

\subsection{Structure of the oceanic upper mantle}

In order to understand the physical properties of these high frequency phases, 

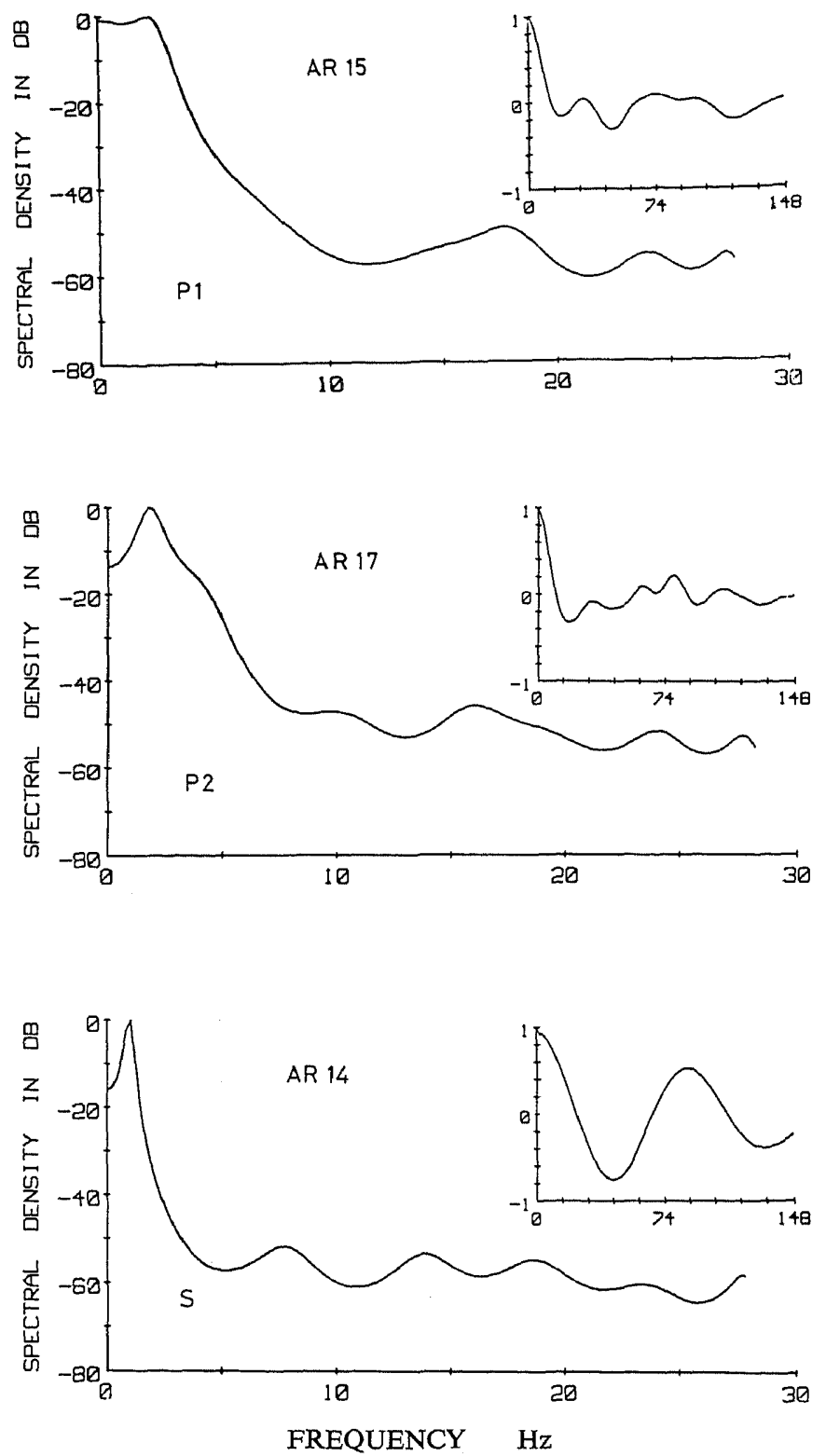

Fig. 12b. Spectra and autocorrelation functions for intervals $P_{1}, P_{2}$ and $S$ shown in Fig. 12a.

it seems important to investigate their velocities. WALKER (1977a) obtained 8.33 or $8.52 \mathrm{~km} / \mathrm{sec}$ for high frequency $P$ phases and 4.7 or $4.77 \mathrm{~km} / \mathrm{sec}$ for $S$ phases in the Pacific. Later he found $7.76 \mathrm{~km} / \mathrm{sec}$ for somewhat different $\mathrm{P}$ 
phases (Walker, 1977b). Shimamura and Asada (1976) and Shimamura et al. (1977) obtained $8.64 \mathrm{~km} / \mathrm{sec}$ for $\mathrm{P}$ waves and $4.88 \mathrm{~km} / \mathrm{sec}$ for $\mathrm{S}$ phases in the OBS study in the north western Pacific. Apparent velocity is estimated as $8.2 \mathrm{~km} / \mathrm{sec}$ or thereabout for $\mathrm{P}$ phases treated in this paper (OucHI et al., 1981).

Taking frequency properties and apparent velocity into account, high frequency $\mathrm{P}$ and $\mathrm{S}$ waves seem to be propagated within the uppermost mantle. Most popular interpretation is due to the high $Q$ properties of the oceanic lithosphere or the slab (e.g., Molnar and Oliver, 1969). But this cannot account for the spectral properties of seismic waves, that is, spectral sharpening or frequency band selection of 5-10 Hz. STEPHENS and ISACKS (1977) and MANTOVANI et al. (1977) regarded " $\mathrm{S}_{\mathrm{n}}$ " as higher mode of Love waves and called "lid wave." This seems quite promising as an explanation for the observed $S$ waves, although it is not certain whether this wave guide would also explain $\mathrm{P}$ waves. SHURBET $(1962,1964)$ considered a thin low velocity zone in the uppermost mantle from the analogy of Sofar layer for T phases. Recently Fuchs and ScHulz (1976) proposed a more refined idea for the upper mantle structure. They considered that high velocity lenses are imbedded in "normal" upper mantle material which serve as a possible wave guide for teleseismic transmission of high frequency phases.

Recent seismological observations have revealed high varieties of the velocity structure of the oceanic lithosphere and high velocity $(>8.4 \mathrm{~km} / \mathrm{sec})$ layers have been found in many regions (e.g., ASADA and SHIMAMURA, 1976; SHIMAMURA and AsadA, 1976; Walker, 1977a; Kasahara and Harvey, 1977; Ouchi, 1977). Higher velocities than $8.4 \mathrm{~km} / \mathrm{sec}$ have also been found locally near Moho in various parts of the Pacific by SUTrON et al. (1971), DeN et al. (1969), ZVEREV (1970), Kosminskaya et al. (1972) and OuCHI (1977), which may imply the existences of thin and high velocity layers or lenses (FUCHS and SCHULz, 1976). Thus a multi-stratified velocity structure with thin and high velocity layers is expected for the oceanic lithosphere. And it is quite possible that such a laminated velocity structure plays a role of "wave guides" of high frequency phases as suggested by Fuchs and Schulz (1976). The high frequency $\mathrm{P}$ and $\mathrm{S}$ phases observed at the bottom of the Mariana basin might be the one which are trapped between very thin layers, maybe thinner than a few kilometers or several hundreds meters. Lower frequencies than $5 \mathrm{~Hz}$ cannot be trapped in such thin layers while waves having frequencies higher than $10 \mathrm{~Hz}$ will be scattered by inhomogeneities of which the scale length is smaller than those of these thin layers. These effects will produce the sharpening of spectra of seismic waves covering a range of $5-10 \mathrm{~Hz}$ as shown in the previous sections.

\section{Conclusions}

The results of this work are summarized as follows:

(1) Using autoregressive models of 10-30th order, the spectrum of high 
frequency $\mathrm{P}$ and $\mathrm{S}$ waves observed at the bottom of the Mariana basin are analyzed appropriately.

(2) Both predominant frequencies and wave energies of earthquakes from the Mariana arc $(\mathrm{S}-\mathrm{P}>50 \mathrm{sec})$ are confined in a certain narrow range at fairly high frequencies, $6-10 \mathrm{~Hz}$ for $\mathrm{P}$ waves and $5.5-9 \mathrm{~Hz}$ for $\mathrm{S}$ waves.

(3) These high frequency phases are also characterized by their unusually long duration.

(4) These facts indicate the existence of some intrinsic mechanisms peculiar to the oceanic region which give rise to high frequency $(5-10 \mathrm{~Hz})$ transmissions of seismic waves. These phases may be excited by a highly laminated structure of the oceanic lithosphere and they may be trapped among the very thin and high velocity layers. Such a velocity structure of the oceanic lithosphere seem to be consistent with the recent seismological observations in the oceanic region.

I wish to thank Dr. S. Nagumo for helpful discussions during the course of this study. I am also indebted to Drs. J. Kasahara, M. Saito, and K. Takano for their enlightening suggestions. Dr. C. Frohlich kindly read the manuscript and made many valuable suggestions.

\section{REFERENCES}

AKaIKe, H., Fitting autoregressive models for prediction, Ann. Inst. Statist. Math., 21, 243-247, 1969a.

AKAIKE, H., Power spectrum estimation through autoregressive model fitting, Ann. Inst. Statist. Math., 21, 407-419, 1969 b.

Asada, T. and H. Shimamura, Observation of earthquakes and explosions at the bottom of the Western Pacific: Structure of oceanic lithosphere revealed by longshot experiment, in The Geophysics of the Pacific Ocean Basin and Its Margin, Geophys. Monogr. Ser., ed. G. H. Sutton, M. H. Manghnai, and R. Moberly, Vol. 19, pp. 135-153, Am. Geophys. Union, Washington, D. C., 1976.

Ashida, Y. and M. SArto, Design of digital Chebyshev filters, Butsuri-Tankō, 23(1), 6-19, 1970 (in Japanese).

Barazangi, M., B. Isacks, and J. Oliver, Propagation of seismic waves through and beneath the lithosphere that descends under the Tonga Island arc, J. Geophys. Res., 77, 952-958, 1972.

BÁrt, M., Propagation of $S_{n}$ and $P_{n}$ to teleseismic distances, Pure Appl. Geophys., 64, 19-30, 1966.

Box, G. E. and G. H. Jenkins, Time Series Analysis: Forecasting and Control, pp. 46-84, HoldenDay, San Francisco, 1970.

Brune, J. and J. DoRman, Seismic waves and earth structure in the Canadian shields, Bull. Seismol. Soc. Am., 53, 167-210, 1963.

Den, N., W. J. Ludwig, S. Murauchi, J. I. Ewing, H. Hotta, N. T. Edgar, T. Yoshix, T. Asanuma, K. Hagrwara, T. Sato, and S. Ando, Seismic-refraction measurements in the Northwest Pacific Basin, J. Geophys. Res., 74, 1421-1434, 1969.

Fuchs, K. and K. SchuLz, Tunneling of low-frequency waves through the subcrustal lithosphere, J. Geophys., 42, 175-190, 1976.

HIRN, A., L. Steinmetz, R. KIND, and K. Fuchs, Long range profiles in western Europe: II. Fine structure of the lower lithosphere in France (southern Bretagne), Z. Geophys., 39, 363-384, 1973. 
Kasahara, J. and R. R. Harvey, Seismological evidence for the high-velocity zone in the Kuril trench area from ocean bottom seismometer observations, J. Geophys. Res., 82, 3805-3814, 1977.

Khalturin, V. I., T. G. Rantian, and P. Molnar, The spectral content of Pamir-Hindu Kush intermediate depth earthquakes: Evidence for a high- $Q$ zone in the upper mantle, J. Geophys. Res., 82, 2931-2943, 1977.

Kosminskaya, I. P., N. N. Puzyrev, and A. S. Alexeyev, Explosion seismology: Its past, present and future, in The Upper Mantle (A. R. Ritsema ed.), Tectonophysics, 13, 309-323, 1972.

Latham, G. V. and G. H. Sutton, Seismic measurements of the ocean floor, J. Geophys. Res., 71, 2545-2573, 1966.

Mantovani, E., F. Schwab, H. Liao, and L. Knopoff, Teleseismic $S_{n}$ : A guided wave in the mantle, Geophys. J. R. Astron. Soc., 51, 709-726, 1977.

Mitronovas, W., B. Isacks, and L. SeEBer, Earthquake locations and seismic wave propagation in the upper $250 \mathrm{~km}$ of the Tonga Island arc, Bull. Seismol. Soc. Am., 59, 1115-1135, 1969.

Molnar, P. and J. Oliver, Lateral variations of attenuation in the upper mantle and discontinuities in the lithosphere, J. Geophys. Res., 74, 2648-2682, 1969.

NAgumo, S. and J. Kasahara, Ocean-bottom seismograph study of the western margin of the Pacific, in The Geophysics of the Pacific Ocean Basin and Its Margin, Geophys. Monogr. Ser., ed. G. H. Sutton, M. H. Manghnai, and R. Moberly, Vol. 19, pp. 155-167, Am. Geophys. Union, Washington, D. C., 1976.

Nagumo, S., S. Hasegawa, S. Koresawa, and H. KobaYashi, Ocean-bottom seismographic observation at the offside of Japan trench near the Erimo seamount-Seismic activity of the oceanic lithosphere and velocity structure around the geophysical "ocean-continent boundary," Bull. Earthq. Res. Inst., 48, 769-792, 1970.

Oliver, J. and B. IsACKs, Deep earthquake zones, anomalous structures in the upper mantle, and the lithosphere, J. Geophys. Res., 72, 4259-4275, 1967.

OUCHI, T., OBS study on the seismicity and spectral structure of seismic waves in the Mariana region, $\mathrm{Ph}$. D. Thesis, Univ. Tokyo, 1977 (in Japanese).

OUCHI, T. and S. NAGUMO, On the application of the maximum entropy method to the spectral analysis of seismic signals, Bull. Earthq. Res. Inst., 50, 359-384, 1975 (in Japanese).

OUChI, T., S. NAGUMO, and S. KorESAWA, Ocean bottom seismometer study on the seismic activity in the Mariana Island arc region, Bull. Earthq. Res. Inst., 56, 43-65, 1981.

ShImamura, H. and T. AsAdA, Apparent velocity measurements on an oceanic lithosphere, Phys. Earth Planet. Int., 13, 15-22, 1976.

Shimamura, H., T. Asada, and M. Kumazawa, High shear velocity layer in the upper mantle of the western Pacific, Nature, 269, 680-682, 1977.

Sfrurber, D. H., The high-frequency P and S phases from the West Indies, Bull. Seismol. Soc. Am., 52, 957-962, 1962.

Shurber, D. H., The high-frequency $\mathrm{S}$ phase and structure of the upper mantle, J. Geophys. Res., 69, 2065-2070, 1964.

StePHENS, C. and B. ISACKs, Toward an understanding of $S_{\mathrm{n}}$ : Normal modes of Love waves in an oceanic structure, Bull. Seismol. Soc. Am., 67, 69-78, 1977.

Surton, G. H. and D. A. WALKER, Oceanic mantle phases recorded on seismographs in the Northwestern Pacific at distances between $7^{\circ}$ and $40^{\circ}$, Bull. Seismol. Soc. Am., 62, 631-655, 1972.

Sutron, G. H., G. L. MAYNARD, and D. M. Hussong, Widespread occurrence of a high-velocity basal layer in the Pacific crust found with repetitive sources and sonobouys, in The Structure and Physical Properties of the Earth's Crust, Geophys. Monogr. Ser., ed. J. G. Heacock, Vol. 14, pp. 193-209, Am. Geophys. Union, Washington, D. C., 1971. 
TJøSTheim, D., A utoregressive representation of seismic P-wave signals with an application to the problem of sh ort-period discriminants, Geophys. J. R. Astron. Soc., 43, 269-291, 1975.

TsumURA, K., Determination of earthquake magnitude from duration of oscillation, Zisin ( $J$. Seismol. Soc. Japan), Ser. 2, 20, 30-40, 1967 (in Japanese).

ULRYCH, T. J. and T. N. Bishop, Maximum entropy spectral analysis and autoregressive decomposition, Rev. Geophys. Space Phys., 13, 183-200, 1975.

Utsu, T., Anomalies in a seismic wave velocity and attenuation associated with a deep earthquake zone (I), J. Fac. Sci. Hokkaido Univ., Ser. 7, Geophysics, 3, 1-25, 1967.

WALKer, D. A., High frequency $\mathrm{P}_{\mathrm{n}}$ and $\mathrm{S}_{\mathrm{n}}$ phases recorded in the western Pacific, J. Geophys. Res., 82, 3350-3360, 1977a.

WALKER, D. A., High-frequency $P_{n}$ phases observed in the Pacific at great distances, Science, 197, 257-259, 1977b.

WALKER, D. A. and G. H. Surron, Oceanic mantle phases recorded on hydrophones in the Northwestern Pacific at distances between $9^{\circ}$ and $40^{\circ}$, Bull. Seismol. Soc. Am., 61, 65-78, 1971.

WATANABE, H., Determination of earthquake magnitude at regional distance in and near Japan, Zisin (J. Seismol. Soc. Japan), Ser. 2, 24, 189-200, 1971 (in Japanese).

ZVEREv, S. M., Problems in seismic studies of the oceanic crust, Izv. Acad. Sci. USSR, Phy's. Solid Earth, 4, 237-246, 1970 (English Transl.). 